\title{
Rancang Bangun Sistem Kontrol dan Pemantauan Serikultur Menggunakan Mikrokontroler Berbasis Internet-of-Things
}

\author{
Bimo Fajrie Alwaaritsi ${ }^{1}$, Toto Tohir ${ }^{2}$, Dedi Aming ${ }^{3}$ \\ 1,2,3 Jurusan Teknik Elektro, Politeknik Negeri Bandung, Bandung 40012 \\ ${ }^{1}$ E-mail: bimofajrie@gmail.com \\ ${ }^{2}$ E-mail: toto.tohir@polban.ac.id \\ ${ }^{3}$ E-mail:deam2k@yahoo.com
}

\begin{abstract}
ABSTRAK
Kegiatan serikultur mempunyai peranan yang penting dan menentukan tinggi atau rendahnya produksi serta kualitas kokon yang dihasilkan. Juga sangat bergantung pada ketelitian dan ketekunan saat pemeliharaan ulat sutera. Pemeliharaan ulat sutera yang kompleks seringkali membuat petani sutera bingung dalam pelaksanaan pemeliharaannya sehingga menurunkan minat petani untuk membudidayakan ulat sutera. Di sisi lain permintaan pasar terhadap produk sutera semakin tinggi. Adanya ruang pemeliharaan ulat sutera dengan sistem kontrol dan pemantauan di dalamnya menjawab permasalahan tersebut. Tujuan dari penelitian ini yaitu merancang dan membangun sistem kontrol dan pemantauan ruangan pemeliharaan ulat sutera. Dengan menggunakan sensor DHT 22 untuk mendeteksi suhu sebesar $\left(25^{\circ} \mathrm{C}-28^{\circ} \mathrm{C}\right)$ dan kelembapan sebesar $(65 \%-85 \%)$. Serta aktuator berupa exhaust fan, humidifier dan heater. Kemudian data dari sensor akan diterima dan dikirimkan oleh modul Wi-Fi ESP32 dengan menggunakan teknologi Internet-of-Things (IoT) ke gawai Android. Pada akhirnya aplikasi Android berguna untuk pemantauan suhu, kelembapan dan kondisi aktuator pada ruangan serikultur dengan menggunakan MIT App Inventor 2. Dengan menggunakan metode Internet-of-Things (IoT), sistem kontrol dan pemantauan ruangan pemeliharaan ulat sutera menjadi praktis dan mudah diakses.
\end{abstract}

\section{Kata Kunci}

Serikultur, IoT, Kontrol, Pemantauan, Android

\section{PENDAHULUAN}

Ulat sutera sangat rentan terhadap perubahan kondisi lingkungan seperti temperatur dan kelembapan [1]. Sehingga dalam pemeliharaannya harus mengikuti ketentuan teknis pemeliharaan yang berlaku, untuk menghindari jumlah ulat sutera yang mati atau menjaga perkembangan ulat sutera dan menghasilkan kokon yang berkualitas baik.

IoT pada dasarnya adalah kombinasi Operational Technology (OT) dan Information Technology (IT) yang memungkinkan data mesin tidak terstruktur untuk dianalisis dan diolah agar untuk peningkatan kinerja [2]. Penerapan IoT pada bidang serikultur dapat membantu untuk meningkatkan kuantitas hasil kokon yang diproduksi. Pemeliharaan ulat sutera merupakan tahapan yang spesifik dan krusial dari kegiatan persuteraan alam mengingat pertumbuhan ulat sutera yang sangat cepat dan sangat dipengaruhi oleh kondisi lingkungan. Iklim didalam ruang pemeliharaan berpengaruh sebesar 37\% terhadap kokon yang dihasilkan [3].

Menurut pengamatan Krishnaswami, ulat sutera dalam semua instar dapat hidup normal pada suhu maksimum dan minimum, berkisar $30^{\circ} \mathrm{C}$ dan $20^{\circ} \mathrm{C}$, tanpa akibat buruk bila pengaruh-pengaruh itu tidak berlangsung lama [4]. Seperti pada penelitian C. Offord, et al. Pengaruh efek lingkungan pada pemintalan dengan mengukur kelembapan dan suhu pada sifat fisik kepompong Bombix mori dimana ulat sutera ditempatkan pada kondisi lingkungan yang berbeda kemudian data diolah menggunakan Matlab, yang berpengaruh pada bentuk kokon dan warna kokon [5]. Dari permasalahan tersebut maka para peneliti telah membuat berbagai macam cara untuk pemantauan sistem serikultur. Seperti A. Duque-Torres et al. yang merancang prototipe untuk pemantauan suhu, kelembapan dan cahaya pada inkubator ulat sutera menggunakan Raspberry Pi 3 dan Google Drive. Informasi yang telah terbaca oleh sensor diunggah ke Google Drive menggunakan komunikasi Wi-Fi sehingga pengguna dapat mengakses data yang tersimpan pada Google Drive menggunakan gawai dengan akun yang terdapat username dan password [6].

Poornima et al. melakukan pengembangan yaitu kontrol suhu, kelembapan dan makanan ulat sutera pada poly house menggunakan mikrokontroler Arduino Mega dan sensor TCS320, RTC DS1307. Relai yang terhubung ke Arduino berguna untuk mengatur catu daya ke motor DC, exhaust fan. Lampu pijar dan exhaust fan berguna untuk mengatur suhu dan kelembaban sesuai kisaran yang ditentukan [7]. Pemberitahuan suhu, kelembapan dan kualitas udara melalui SMS telah diteliti oleh Kumar et al. yaitu IoT berbasis WPAN dan Image Processing. Pemantauan suhu dan kelembapan memakai sensor yang terhubung dengan Arduino. Sensor DHT11 dapat mendeteksi suhu dan kelembapan, data dari sensor tersebut dikirim melalui modul GSM900. Apabila suhu $\left(<22^{\circ} \mathrm{C}\right.$ dan $\left.>26{ }^{\circ} \mathrm{C}\right)$ dan kelembapan $(<65 \%$ 
dan $>85 \%$ ) mencapai titik kritikal maka GSM900 akan mengirim SMS ke pengguna [8].

Tujuan dari penelitian ini yaitu merancang dan membangun sistem pemantauan ruangan pemeliharaan ulat sutera sehingga dapat memantau ruangan pemeliharaan ulat sutera, yang menggunakan sensor DHT22 untuk mendeteksi suhu sebesar $\left(25^{\circ} \mathrm{C}-28^{\circ} \mathrm{C}\right)$ dan kelembapan sebesar $(65 \%$ - 85\%).

\section{PERANCANGAN SISTEM}

Perancangan sistem kontrol dan pemantauan ini meliputi perangkat keras dan perangkat lunak. Perangkat keras seperti pembuatan miniatur ruangan budidaya ulat sutera dan panel. Sedangkan pada perangkat lunak mengenai Firebase dan App Inventor.

\subsection{Perangkat Keras}

Spesifikasi dari perangkat keras pada sistem ini dapat terlihat pada Tabel 1, sedangkan blok diagram dari perancangan sistem dapat terlihat pada Gambar 1 .

\begin{tabular}{lc}
\multicolumn{2}{c}{ Tabel 1. Spesifikasi perangkat keras } \\
\hline \multicolumn{2}{c}{ Spesifikasi } \\
\hline Modul mikrokontroler & - ESP32-S \\
Sensor & - DHT22 \\
Catu daya & - Power Supply 5VDC; 24VDC \\
Bahan miniatur & - Kayu plywood dan albasia \\
\hline
\end{tabular}

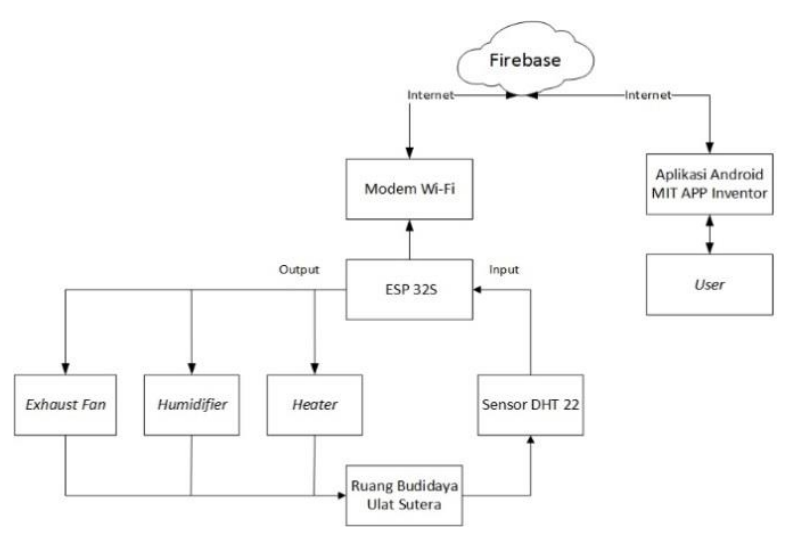

Gambar 1. Blok diagram perangkat keras

Ulat sutera merupakan hewan berdarah dingin, maka kecepatan pertumbuhannya sangat tergantung kepada kondisi lingkungan tempat hidupnya, sehingga lama periode larva, pupa dan ngengat tersebut tidak selalu sama. Seperti yang dijelaskan pada gambar 1, DHT22 berguna sebagai sensor suhu dan kelembaban. Selanjutnya data yang telah terbaca pada sensor akan dikirimkan ke mikrokontroler ESP32-S sebagai pengontrol sistem. Dengan menggunakan Arduino IDE sebagai software untuk pemrograman. ESP32-S akan membandingkan suhu dan kelembaban yang diterima. Jika suhu dan kelembaban diluar dari range habitat hidup optimal ulat sutera yaitu suhu sebesar $25-28^{\circ} \mathrm{C}$ dan kelembapan 65-85 \%, maka akan dikirimkan sinyal untuk mengaktifkan exhaust fan, humidifier dan heater sambil tetap memantauan suhu dan kelembapan. Jika suhu dan kelembapan sudah kembali normal maka akan dikirimkan sinyal untuk menonaktifkan exhaust fan, humidifier dan heater.

Kemudian ESP32-S mengirim data ke Firebase yang dikirim melalui internet sehingga sistem dapat beroperasi menggunakan gawai Android. Dengan database yang di-host pada cloud menggunakan Firebase. Data akan terintegrasi dan disinkronkan secara real-time ke setiap pengguna yang terhubung. Sehingga pengguna akan menerima update data terbaru secara otomatis saat menggunakan aplikasi. MIT APP Inventor 2 berguna sebagai media pemantauan jarak jauh pada aplikasi Android.

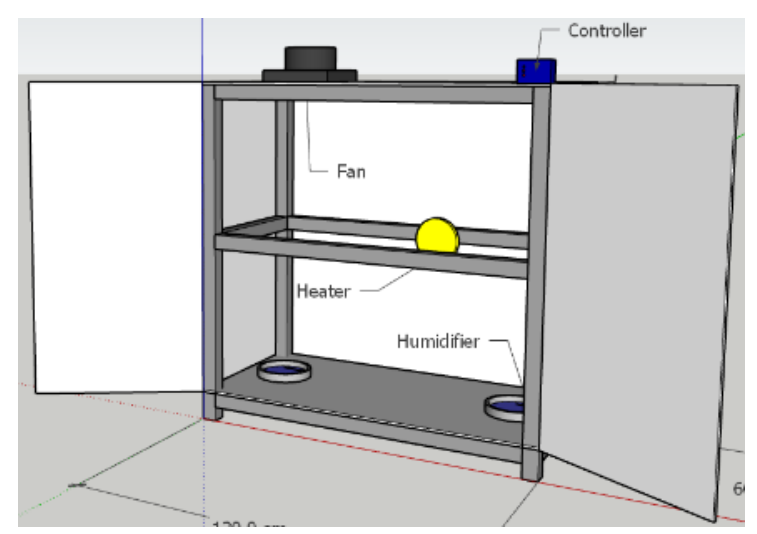

Gambar 2. Perancangan miniatur ruangan serikultur

Perancangan miniatur ruangan serikultur terdiri dari bahan dan dimensi miniatur. Bahan yang berguna sebagai kontruksi adalah kayu albasia dan plywood dengan dimensi kontruksi yaitu panjang $120 \mathrm{~cm}$, lebar $60 \mathrm{~cm}$ dan tinggi $120.9 \mathrm{~cm}$. Terdapat satu buah exhaust fan dan satu buah panel kontroler yang dipasang pada bagian atas miniatur. Memakai satu buah Ceramic heat lamp pada langit-langit miniatur, sedangkan dua buah humidifier terletak pada bagian dasar miniatur. Agar lebih jelas dapat terlihat pada gambar 2.

\subsection{Perangkat Lunak}

Perancangan perangkat lunak meliputi diagram alir dari sistem perangkat keras dan sistem antarmuka. Adapun diagram alir dari sistem perangkat keras dapat terlihat pada Gambar 3. 


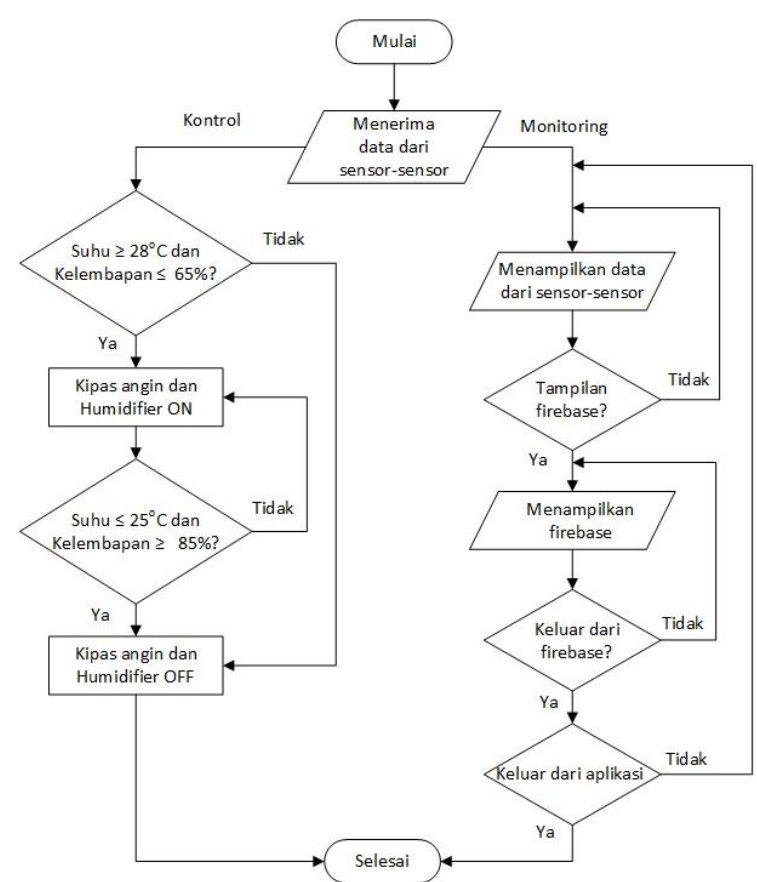

Gambar 3. Diagram alir sistem

Merancang perangkat lunak berupada database dan MIT App Inventor 2. Firebase nanti akan menyimpan data yang dikirim oleh ESP32 berupa suhu, kelembapan dan kondisi aktuator-aktuator. Firebase merupakan platform yang dapat menyimpan data atau hosted di cloud. Google sepenuhnya mengelola dan megoperasikan komponen backend pada Firebase [9]. Penulis memilih Firebase karena mempermudah sehingga tidak perlu membuat backend.

Sedangkan untuk tampilan pada gawai Android penulis menggunakan MIT App Inventor 2 karena memudahkan pembuatan aplikasi tanpa harus mempelajari atau menggunakan bahas pemrograman yang terlalu rumit. Sehingga dalam mendesain aplikasi Android dapat membuat sesuai keinginan dan kebutuhan menggunakan layout dan komponen yang telah tersedia dalam platform.

MIT App Inventor 2 memiliki dua laman, yaitu laman designer yang berfungsi untuk mendesain tampilan aplikasi sesuai dengan kebutuhan serta laman block untuk memprogram aplikasi Android [10]. Pada aplikasi yang ini terdapat beberapa tampilan dengan rincian:

- Screen 1: Loading Screen

- Screen 2: Menu Utama

- Screen 3: Informasi umum ulat sutera

- Screen 4: Pemantauan sensor dan aktuator ruangan serikultur

- Screen 5: Alur Produksi Serikultur

Berikut merupakan diagram alir aplikasi sebagai tampilan pada gawai Android.

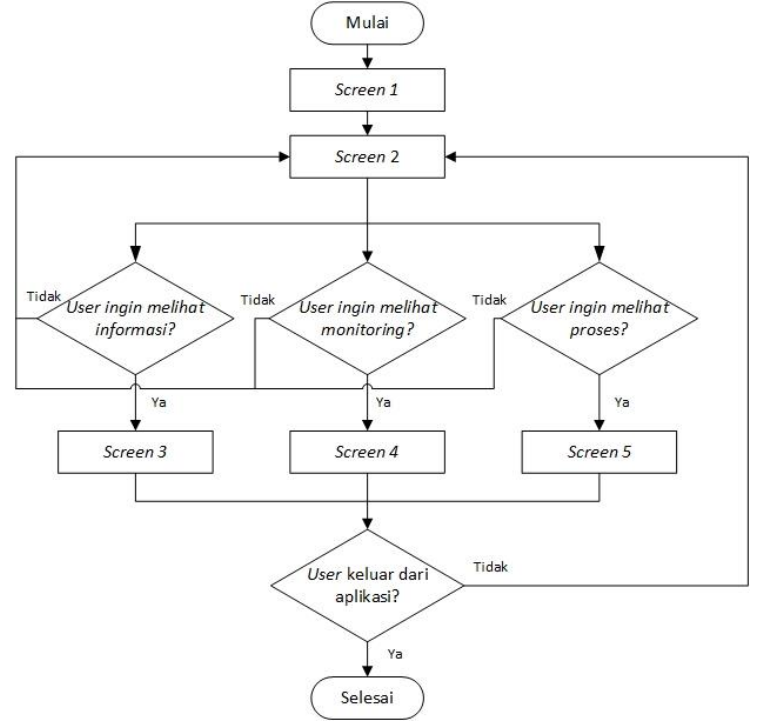

Gambar 4. Diagram alir kerja aplikasi

\section{HASIL DAN PEMBAHASAN}

Hasil implementasi dari sistem dalam bentuk perangkat keras dapat terlihat pada Gambar 4. Selanjutnya melakukan pengujian terhadap subsistem sensor dan subsistem antarmuka.

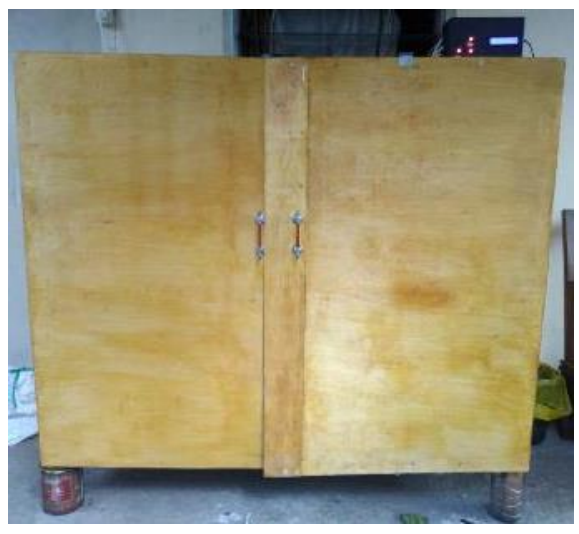

Gambar 4. Implementasi perangkat keras

\subsection{Pengujian Sensor}

Sensor DHT22 berguna sebagai sensor yang akan mendeteksi suhu dan kelembapan pada ruangan serikultur. Sebelum mengimplementasi harus melakukan pengujian kalibrasi dengan cara membandingkan hasil pembacaan sensor DHT22 dengan alat ukur higrometer dan termometer.

$$
e(\%)=\frac{\mid \text { data_Sensor-data_Alatukur } \mid}{\text { data_Alatukur }} \times 100
$$




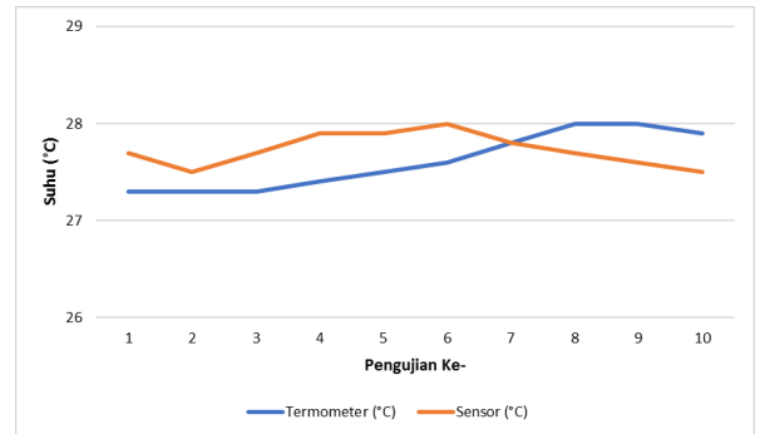

Gambar 5. Grafik pengukuran suhu

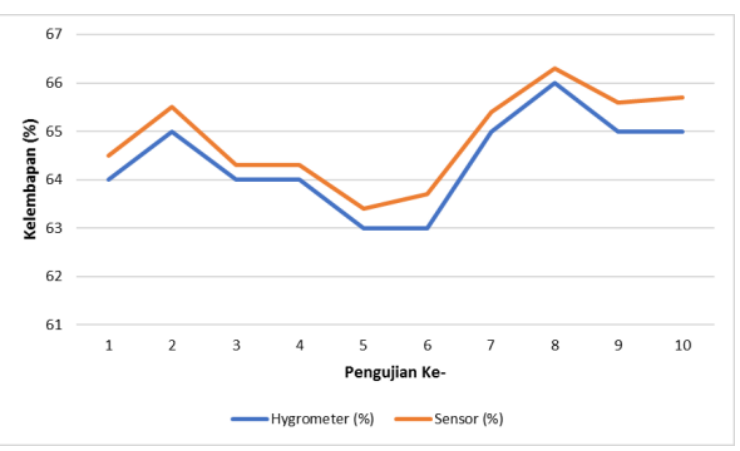

Gambar 6. Grafik pengukuran kelembapan

Berdasarkan hasil pengujian sensor tersebut dan dibandingkan dengan alat ukur, diperoleh nilai kesalahan rata-rata untuk setiap alat ukur. Nilai kesalahan tersebut diperoleh berdasarkan perhitungan pada persamaan (1).

Nilai error rata-rata suhu adalah $0.43 \%$. Maka nilai tingkat akurasi sensor suhu adalah 100\%-0.43\% yaitu sebesar $99.57 \%$. Nilai error rata-rata kelembapan adalah $0.73 \%$. Maka nilai tingkat akurasi sensor kelembapan adalah $100 \%-0.73 \%$ yaitu sebesar $99.27 \%$.

\subsection{Pengujian Perangkat Antarmuka}

Pengujian Firebase yaitu dengan cara membuka web browser, lalu akses situs https://Firebase.google.com, kemudian login dengan menggunakan akun google. Cari proyek yang telah dibuat pada Firebase Projects, kemudian masuk pada fitur real-time database. Maka akan mendapatkan hasil berupa data yang telah dikirim oleh ESP32-S. Gambar IV.3 dan IV.4 merupakan kondisi real-time database sebelum dan sesudah menerima data dari ESP32S.

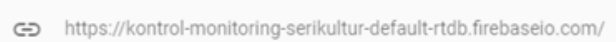

—SUHU: 25.9

Gambar 8. Tampilan real-time database
Perancangan antarmuka dalam bentuk aplikasi Android menggunakan MIT App Inventor 2. Screen 1 merupakan loading screen pada aplikasi "My Sericulture". Ketika inisialisasi Screen1 kemudian otomatis membuka Screen2. Screen 2 merupakan menu utama atau navigasi untuk memudahkan pengguna mengakses aplikasi sesuai dengan kebutuhan. Didalamnya terdapat pilihan untuk mengakses laman Serikultur, Monitoring Ruangan atau Alur Produksi Serikultur. Screen3 merupakan informasi umum mengenai serikultur agar mempermudah pengguna untuk paham mengenai ulat sutera secara umum. Pada saat mengakses screen4, laman akan memunculkan data dari Firebase berupa keterangan suhu dan kelembapan serta kondisi ON/OFF dari exhaust fan, humidifier dan heater. Screen 5 merupakan alur produksi serikultur agar pengguna mengetahui tahapan-tahapan pada budidaya ulat sutera mulai dari hilir hingga hasil akhir berupa kepompong.

Adapun tampilan aplikasi Android yang dihasilkan dapat terlihat pada Gambar 9.

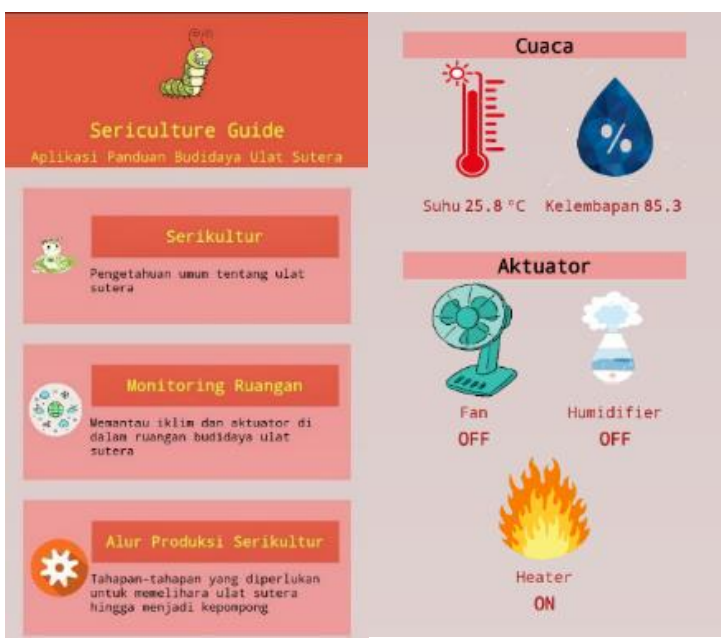

Gambar 9. Tampilan aplikasi Android

\subsection{Analisis Kerja Sistem Kontrol}

Untuk mengetahui sistem kontrol pada ruang budidaya ulat sutera dapat mengendalikan suhu diantara $25^{\circ} \mathrm{C}$ $28^{\circ} \mathrm{C}$ dan kelembaban $65 \%$ - $85 \%$ maka diperlukan pengujian. Pengambilan data suhu dan kelembapan menggunakan dua cara yaitu dari sensor DHT22 yang terpasang pada ruangan terkontrol dan alat ukur berupa termometer serta higrometer yang dipasang pada ruangan yang tidak terkontrol. Kemudian melakukan pencatatan data secara manual sebanyak tiga kali dalam sehari pada jam 07:00, jam 12:00 dan jam 17:00. 


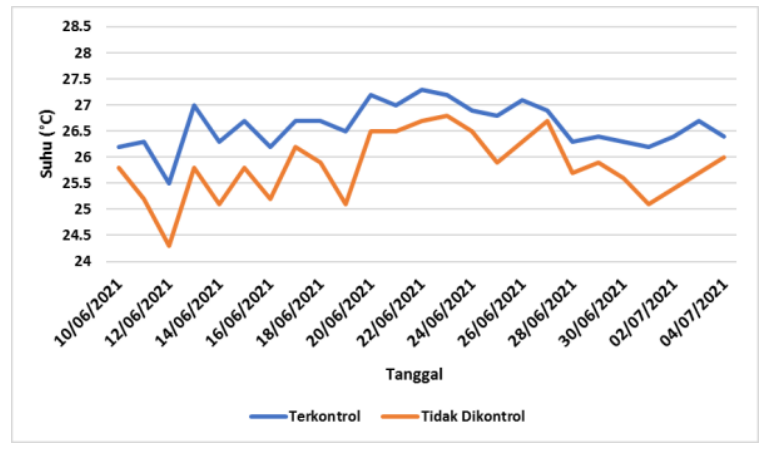

Gambar 10. Pengamatan suhu pada ruangan terkontrol dan tidak terkontrol

Dari gambar 10 dapat terlihat bahwa suhu di dalam ruangan pemeliharaan ulat sutera lebih tinggi daripada ruangan yang tidak terkontrol. Namun pada suhu ruangan terkontrol tidak pernah kurang dari batas minimum suhu pemeliharaan yaitu $25^{\circ} \mathrm{C}$ dan melebihi batas maksimum suhu pemeliharaan yaitu $28^{\circ} \mathrm{C}$, sehingga hal ini sudah sesuai dengan acuan kondisi suhu ruangan serikultur yaitu antara $25^{\circ} \mathrm{C}-28^{\circ} \mathrm{C}$. Sedangkan pada ruangan tidak terkontrol perubahan suhu lebih fluktuatif dan suhu pernah mencapai nilai $24.3^{\circ} \mathrm{C}$ dimana lebih rendah dari batas minimum suhu pemeliharaan ulat sutera.

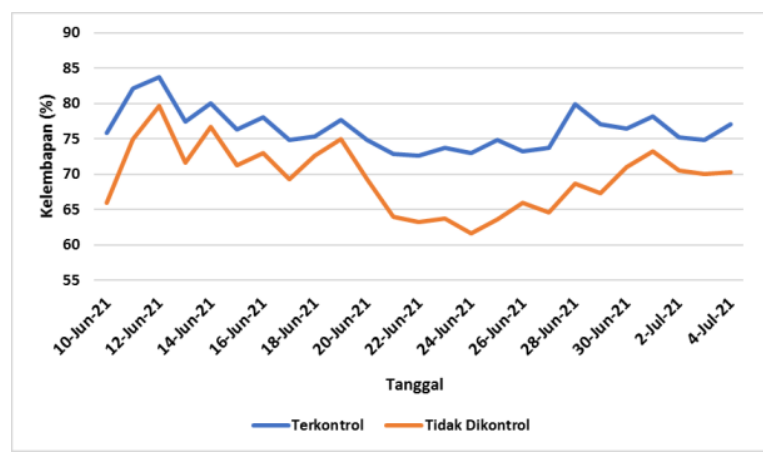

Gambar 11. Pengamatan kelembapan pada ruangan terkontrol dan tidak terkontrol

Dari gambar 11 dapat diketahui bahwa perubahan kelembapan pada ruangan yang tidak terkontrol lebih fluktuatif daripada di dalam ruangan terkontrol. Kelembapan suhu ruangan terkontrol tidak pernah kurang dari batas minimum kelembapan pemeliharaan yaitu $65 \%$ dan melebihi batas maksimum kelembapan pemeliharaan yaitu $85^{\circ} \mathrm{C}$, sehingga hal ini sudah sesuai dengan acuan kondisi kelembapan ruangan serikultur yaitu antara $65 \%-85 \%$. Sedangkan pada ruangan tidak terkontrol perubahan kelembapan pernah mencapai nilai $61.7 \%$ atau lebih rendah dari batas minimum kelembapan pemeliharaan ulat sutera. Hal ini disebabkan karena cuaca lingkungan mempenguhi secara langsung perubahan kelembapan pada ruangan yang tidak terkontrol.

\subsection{Analisis Kualitas Kepompong}

Kepompong yang dipanen dari alat kemudian diambil sebanyak 50 buah untuk dijadikan sampel. Kemudian diuji karakteristik kepompong seperti tebal, panjang dan diameter kulitnya serta berat total dan berat kulitnya saja. Persentase kulit kokon dapat dihitung dengan membandingkan berat total kepompong dengan berat kulitnya saja. Sedangkan untuk warna dapat terlihat langsung dengan mata telanjang. Tabel 2 merupakan perhitungan menggunakan standar deviasi dan pengukuran karakteristik kokon.

\begin{tabular}{|c|c|c|c|}
\hline No & Parameter & $\begin{array}{c}\text { Ruangan } \\
\text { Terkontrol }\end{array}$ & $\begin{array}{c}\text { Ruangan Tidak } \\
\text { Terkontrol }\end{array}$ \\
\hline 1 & Panjang $(\mathrm{cm})$ & $3.055 \pm 0.142$ & $3.012 \pm 0.151$ \\
\hline 2 & $\begin{array}{l}\text { Diameter Luar } \\
(\mathrm{cm})\end{array}$ & $1.845 \pm 0.071$ & $1.824 \pm 0.093$ \\
\hline 3 & Ketebalan $(\mathrm{cm})$ & $0.044 \pm 0.008$ & $0.038 \pm 0.009$ \\
\hline 4 & $\begin{array}{l}\text { Persentase kulit } \\
\text { kokon }(\%)\end{array}$ & $54.2 \%$ & $54.6 \%$ \\
\hline 5 & $\begin{array}{l}\text { Berat total } \\
\text { (g/50pcs) }\end{array}$ & $26.7 \pm 0.06$ & $25.9 \pm 0.08$ \\
\hline 6 & Warna & Putih & Putih \\
\hline
\end{tabular}

Dari tabel di atas dapat terlihat terdapat perbedaan pada parameter-parameter antara pembudidayaan kepompong pada ruangan terkontrol dan ruangan tidak terkontrol. Pada ruangan terkontrol menghasilkan kualitas kokon yang lebih baik dari segi panjang, diameter luar, ketebalan, persentase kulit kokon dan berat total daripada ruangan tidak terkontrol. Hal ini disebabkan karena pada ruangan terkontrol suhu dan kelembapan lebih optimal untuk menunjang saat pemeliharaan ulat sutera. Sedangkan untuk warna kepompong tidak ada perbedaan antara ruangan terkontrol dan tidak terkontrol. Pada umumnya pada kelembapan tinggi akan menghasilkan kepompong bewarna emas kecoklatan. Namun pada penelitian ini hal tersebut dapat dihiraukan karena yang berperan pada warna kepompong adalah gen dari bibit ulat sutera. Dengan memakain bibit ras bivoltine Jepang yang telah melalui berbagai rekayasa genetika dan persilangan sehingga selalu menghasilkan kepompong bewarna putih.

\section{KESIMPULAN}

Perancangan perangkat sistem kontrol dan pemantauan serikultur menggunakan mikrokontroler berbasis internet-of-things (IoT) telah berhasil dan dapat berjalan dengan baik. Aplikasi pada gawai Android berguna untuk mengakses parameter pada miniatur ruangan budidaya ulat sutera. Perancangan sistem pengontrolan dan pemantauan ruangan budidaya ulat sutera ini dapat mempertahankan suhu $25^{\circ} \mathrm{C}-28^{\circ} \mathrm{C}$ dan kelembaban $65 \%-85 \%$ sehingga kondisi iklim di dalam ruangan sesuai dengan ketentuan pemeliharaan ulat sutera yang optimal. Untuk penelitian selanjutnya, perancangan sistem kontrol dan pemantauan ini untuk pemakaian pada ruangan budidaya ulat sutera yang memiliki skala lebih besar. Kemudian pengembangan menjadi sistem komunikasi dua arah agar dapat mengontrol melalui perangkat Android.

\section{UCAPAN TERIMA KASIH}


Tim peneliti mengucapkan terimakasih kepada Politeknik Negeri Bandung, melalui wakil Direktur Akademik atas bantuan pendanaan dengan SK No. B/402/PL1.R1/EP.00.08/2021 kelompok A1.

\section{DAFTAR PUSTAKA}

[1] M. Hussain, M. Naeem, S. A. Khan, M. F. Bhatti, and M. Munawar, "Studies on the influence of temperature and humidity on biological traits of silkworm (Bombyx mori L.; Bombycidae)," p. 8.

[2] L. Barik, "IoT based Temperature and Humidity Controlling using Arduino and Raspberry Pi," IJACSA, vol. 10, no. 9, 2019, doi: 10.14569/IJACSA.2019.0100966.

[3] A. Nunuh, O. Andhikarya, M. Kaomini, and B. Susetyo, "Panduan Serikultur," in Pedoman Teknis Pemeliharan Ulat Sutera, Bandung, Indonesia: SAMBA PROJECT, 2003, p. 59.

[4] Krishnaswami S, "Manual on Sericulture, Silkworm Rearing," vol. 2, Rome: Food and Agricultural Organization of the United Nations, 1973, p. 131.

[5] C. Offord, F. Vollrath, and C. Holland, "Environmental effects on the construction and physical properties of Bombyx mori cocoons," J Mater Sci, vol. 51, no. 24, pp. 10863-10872, Dec. 2016, doi: 10.1007/s10853-016-0298-5.
[6] A. Duque-Torres et al., "A new environmental monitoring system for silkworm incubators," F1000Res, vol. 7, p. 248, Feb. 2018, doi: 10.12688/f1000research.13633.1.

[7] G. R. Poornima, F. Taj, T. M. Gavinya, G. Madhu, and B. N. Madhubala, "Arduino Based Automated Sericulture System," in 2018 3rd IEEE International Conference on Recent Trends in Electronics, Information \& Communication Technology (RTEICT), Bangalore, India, May 2018, pp. 2504-2507. doi: 10.1109/RTEICT42901.2018.9012239.

[8] N. M., S. R., and D. Kumar, "Silkworm Growth Monitoring Smart Sericulture System based on Internet of Things (IOT) and Image Processing," IJCA, vol. 180, no. 18, pp. 29-33, Feb. 2018, doi: 10.5120/ijca2018916514.

[9] D. R. Kornack, "IoT-BASED MONITORING OF INDUCTION MOTOR PERFORMANCE,' Science, vol. 294, no. 5549, pp. 2127-2130, Dec. 2001, doi: 10.1126/science. 1065467.

[10] M. T. Katarine and K. O. Bachri, "SMART ROOM MONITORING MENGGUNAKAN MIT APP INVENTOR DENGAN KONEKSI BLUETOOTH," jurnalelektro, vol. 13, no. 1, pp. 51-66, Oct. 2020, doi: 10.25170/jurnalelektro.v13i1.1824. 